\title{
Triple X Syndrome Woman Presenting as Premature Ovarian Failure
}

\author{
C Chandana, Shreedhar Venkatesh
}

\begin{abstract}
Triple $X$ syndrome is a sex chromosome abnormality characterized by extra $X$ chromosome, occurring in approximately 1 in 1,000 female births. This condition often remains undiagnosed as most of them have normal phenotype, puberty and fertility. We report a case of Triple $X$ syndrome with normal phenotype and intelligence presented with secondary amenorrhea and diagnosed to have premature ovarian failure. This case emphasizes the need for chromosomal analysis in women presenting with premature ovarian failure leading to primary or secondary amenorrhea.
\end{abstract}

Keywords: Triple $X$ syndrome, Premature ovarian failure, Secondary amenorrhea, Karyotyping.

How to cite this article: Chandana C, Venkatesh S. Triple X Syndrome Woman Presenting as Premature Ovarian Failure. Int J Infertility Fetal Med 2013;4(3):96-98.

Source of support Nil

\section{Conflict of interest None}

\section{INTRODUCTION}

Triple $X$ syndrome is a sex chromosome anomaly caused by the presence of an extra $X$ chromosome in females (47, XXX instead of $46, X X)$. It results from nondysjunction of $X$-chromosome during meiotic division. This condition often remains undiagnosed as most of them have normal phenotype, puberty and fertility. It is estimated that only $10 \%$ of individuals with trisomy $X$ are actually diagnosed. We report a case of Triple $X$ syndrome with normal phenotype and intelligence that presented with secondary amenorrhea and diagnosed to have premature ovarian failure.

\section{CASE REPORT}

A 21-year-old girl was seen in the gynecology OPD for secondary amenorrhea. She is the first child to her parents and has one younger brother, her parents were under 30 years at the time of her birth. And her early developmental milestones were normal. She is studying in college and her academic record was good. She attained menarche at the age of 14 years and menstruated regularly till the age of 17 years, then she menstruated irregularly at the intervals of 60 to 120 days till last year. On examination, she was

Date of Received: 05-08-2013

Date of Acceptance: 10-09-2013

Date of Publication: September 2013
$160 \mathrm{~cm}$ tall, weight was $53 \mathrm{~kg}$ and B M I was 18 . She had a female phenotype with breast and pubic hair Tanner stage four developments. A gynecological examination revealed normal vulva and perineum. A $n$ ul trasound of pelvis showed uterus with $52 \times 50 \mathrm{~mm}$, Endometrial thickness was $2 \mathrm{~mm}$ thick and both ovaries were atrophic. Hormonal assay was done, FSH was increased $(80 \mathrm{mlU} / \mathrm{ml})$, Serum estradiol was low $(30 \mathrm{pg} / \mathrm{ml})$. Serum prolactin, thyroid profile and serum cortisol were normal. Karyotyping was done which revealed trisomy $X$ (Fig. 1) and was diagnosed to have premature ovarian failure due to triple $X$ syndrome. Counseling was done to the patient and her parents. She was given conjugated equine estrogen $(0.625 \mathrm{mg} /$ day $)$ from day 1 to 21 and medroxyprogesterone acetate $(10 \mathrm{mg} /$ day) from day 21 to 25 . While taking this regimen, she had cyclical bleeding.

\section{DISCUSSION}

Premature ovarian failure (POF) is defined as cessation of ovarian function before the age of 40 years, associated with el evated gonadotropins, serum levels of $\mathrm{FSH} \geq 40 \mathrm{IU} / \mathrm{L}$ and affects 1 to $3 \%$ of women of reproductive age. ${ }^{1}$ POF occurs in 10 to $28 \%$ of women with primary amenorrhea and 4 to $18 \%$ in those with secondary amenorrhea. ${ }^{2,3}$ Women with POF suffer from anovulation, hypoestrogenism. They present with primary or secondary amenorrhea, infertility, sex steroid deficiency and el evated gonadotropins.

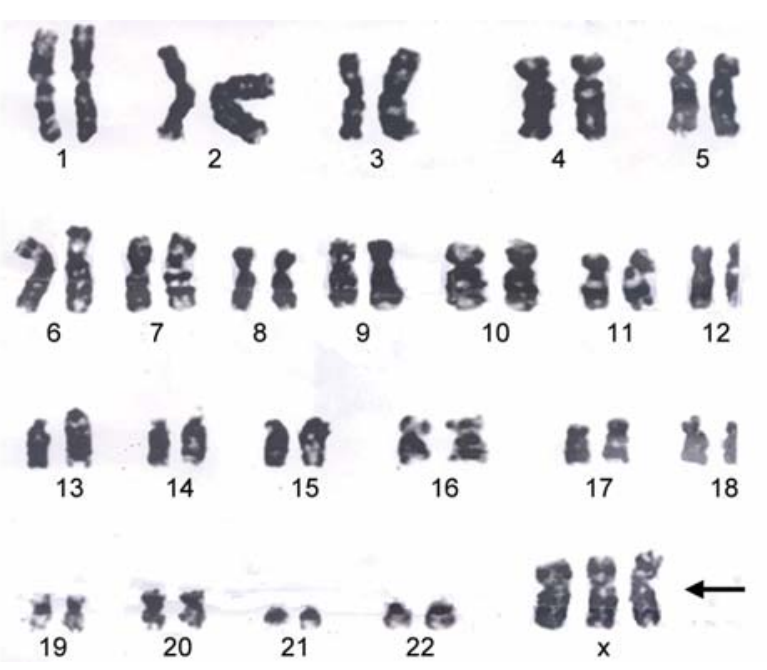

Fig. 1: Karyotyping showing trisomy $X$ 
The etiological causes of POF are highly heterogeneous and include chromosomal, genetic, autoimmune, metabolic, infectious and iatrogenic factors. Genetic causes include $1 / 3$ rd cases of POF. Genetic defects mostly involve the $X$ chromosome, and there may be autosomal involvement. These abnormalities range from a numerical defect like complete deletion of one $X$ (Turner's syndrome) and trisomy $X$ to partial defects in form of deletions, isochromosomes and balanced $X$ autosome translocations. ${ }^{4}$

Triple $X$ syndrome (trisomy $X$ ) was first described by Jacobs in 1959, as super female is a sex chromosomal aneuploidy condition with female phenotype. ${ }^{5}$ Triple $X$ syndrome is a sex chromosome anomaly caused by the presence of an extra $X$ chromosome in females (47, XXX instead of $46, X X)$ ). It results from nondysjunction of $X$-chromosome during meiotic division. It is the most common female chromosomal abnormality, occurring in approximately 1 in 1,000 female births. ${ }^{6} \mathrm{~A}$ s some individuals are only mildly affected or asymptomatic, it is estimated that only $10 \%$ of individuals with trisomy $X$ are actually diagnosed. There is a considerable variation in phenotype, and some individuals mildly affected. Its symptoms vary very widely, including tall stature, hypertel orism, epicanthal folds, clinodactyly, congenital heart disease, seizures, genitourinary and some other anomalies. ${ }^{7}$

These females often have a tall stature than their female peers, not explained by parental heights. ${ }^{8} \mathrm{~A}$ ffected females typically have normal intelligence but lower IQ than that of their siblings. There may be learning difficulties and they tend to have delayed acquisition of certain motor skills, language skills and impaired psychosocial adaptations. ${ }^{9}$ These girls need supportive parents and atmosphere that provides constant stimulation and love for learning and interaction. Our patient presented only with secondary amenorrhea without any other features of triple $X$ syndrome. Pubertal onset, sexual development and fertility are usually normal in these girls. POF has been reported in triple $x$ syndrome. Studies on the prevalence of POF in adolescents or adults with trisomy $X$ have not yet been performed, but in one reported series, 2 of $52(3.8 \%)$ patients with POF had the triple $X$ syndrome. Genetic defects are proposed to cause POF by increasing atresia of ovarian follicles due to apoptosis or failure of follicle maturation and thus decreasing the pool of primordial follicles. ${ }^{10}$

Patients with triple $X$ syndrome may have immune disturbances, as revealed by increased serum IgM levels, and associated with other autoimmune disorders. ${ }^{11}$ Early loss of ovarian function has significant psychosocial sequelae and major health implications nearly 2 -fold agespecific increase in mortality rate has been reported. ${ }^{12}$
POF generates two types of consequence. One is premature hypoestrogenism, which in turn causes the premature aging of several tissues, targets of estrogen action, and thus increasing the risk of osteoporosis, cardiovascular diseases, or neurodegenerative diseases. Hypoestrogenism can nowadays be satisfactorily treated by hormone replacement therapy to be generally given until the age of physiological menopause. The second consequence is infertility. A lthough most patients with triple $X$ syndrome can conceive, a high preval ence ( $50 \%$ ) of cardiac and neural tube defects, malformations of the genitourinary tract and sex chromosomal abnormalities have been reported in their offspring, and most offspring die during early childhood. ${ }^{13}$ The only proven means of achieving pregnancy in infertile women with triple $X$ syndrome is by assisted conception with donor oocytes.

\section{CONCLUSION}

M ost of the triple $X$ syndrome girls have normal female phenotype, pubertal development and fertility. This condition should be kept in mind in evaluating young woman with primary or secondary amenorrhea with POF. O ur case emphasizes the need for chromosomal analysis in women presenting with premature ovarian failure. $M$ anagement essentially involves hormone replacement and infertility treatment, the only proven means for the latter being assisted conception with donated oocytes.

\section{REFERENCES}

1. Coulam CB. Premature gonadal failure. Fertil Steril 1982;38(6): 645-655.

2. Coulam CB, A damson SC, A nnegers J F. Incidence of premature ovarian failure. Obstet Gynecol 1986 A pr;67(4):604-606.

3. A nasti JN. Premature ovarian failure: an update. Fertil Steril 1998 Jul;70(1):1-15.

4. Zinn AR. The X chromosome and the ovary. J Soc Gynecol Investig 2001;8(1):S34-36.

5. Jacobs PA, B aikie A G, B rown W M, M cgregor T N, M aclean N, Harnden DG. Evidence for the existence of the human super female. Lancet 1959 Sep 26;2(7100):423-425.

6. Nielsen J, Wohlert M. Sex chromosome abnormalities found among 34,910 newborn children: results from a 13-year incidence study in A rhus, Denmark. Birth Defects Orig Artic Ser 1990;26(4):209-223.

7. Tartaglia NR, Howell S, Sutherland A, Wilson R, Wilson L. A review of trisomy $X(47, X X X)$. Orphanet J Rare Dis 2010 $M$ ay 11;5:8. doi: 10.1186/1750-1172-5-8.

8. Liebezeit BU, Rohrer TR, Singer H, Doerr HG. Tall stature as presenting symptom in a girl with triple $\mathrm{X}$ syndrome. J Pediatr Endocrinol Metab 2003;16(2):233-235.

9. Rovet J, Netley C, B ailey J, K eenan M, Stewart D. Intelligence and achievement in children with extra $X$ aneuploidy: $a$ longitudinal perspective. A m J Med Genet 1995 Oct 9;60(5): 356-363. 
10. Goswami D, Conway GS. Premature ovarian failure. Hum Reprod U pdate 2005 Jul-A ug; 11(4):391-410.

11. Rhodes $K, M$ arkham RL, M axwell PM, M onk-Jones $M E$. Immunoglobulins and the X-chromosome. Br Med J 1969 A ug 23;3(5668):439-441.

12. Snowdon DA, Kane RL, B eeson WL, Burke GL, Sprafka JM, Potter J, Iso H, Jacobs DR Jr, Phillips RL. Is early natural menopause a biologic marker of health and aging? A $m$ J Public Health 1989 J un;79(6):709-714.

13. Fryns JP, Kleczkowska $A$, Petit $P$, van den Berghe $H$. $\mathrm{X}$-chromosome polysomy in the female: personal experience and review of the literature. Clin Genet $1983 \mathrm{M}$ ay;23(5):341-349.

\section{ABOUT THE AUTHORS}

\section{Chandana (Corresponding Author)}

A ssistant Professor, D epartment of O bstetrics and Gynecology, V ydehi Institute of M edical Sciences and Research Centre, B engal uru, K arnataka India, Phone: 7795826846, e-mail: chandanachandregowda@gmail.com

\section{Shreedhar Venkatesh}

Professor and H ead, Department of O bstetrics and Gynecology, $V$ ydehi Institute of Medical Sciences and Research Centre, Bengaluru Karnataka, India 